\title{
Risk of Conversion to Dementia in a Mild Behavioral Impairment Group Compared to a Psychiatric Group and to a Mild Cognitive Impairment Group
}

Fernando E. Taragano ${ }^{a, b, *}$, Ricardo F. Allegria ${ }^{a, b}$, Silvina L. Heisecke ${ }^{a, b}$, María I. Martelli ${ }^{\text {, }}$ Mónica L. Feldman ${ }^{\mathrm{b}}$, Viviana Sánchez ${ }^{\mathrm{b}}$, Virginia A. García ${ }^{\mathrm{b}}$, Graciela Tufro ${ }^{\mathrm{b}, \dagger}$, Diego M. Castro $^{\mathrm{b}}$, Patricio Perez Leguizamón ${ }^{\mathrm{b}}$, Verónica Guelar ${ }^{\mathrm{b}}$, Eva Ruotolo ${ }^{\mathrm{b}}$, Cecilia Zegarra ${ }^{\mathrm{b}}$ and Carol Dillon ${ }^{\mathrm{a}} \mathrm{b}$ ${ }^{a}$ National Scientific Research Council - CONICET, Buenos Aires, Argentina

${ }^{\mathrm{b}}$ Neuropsychiatry Research Unit, CEMIC University Hospital, Galvan, Buenos Aires, Argentina

Handling Associate Editor: Krista Lanctôt

Accepted 28 November 2017

\begin{abstract}
.
Background: There is insufficient available information on behavioral changes in the absence of cognitive impairment as factors increasing the risk of conversion to dementia.

Objective: To observe and analyze patients with mild behavioral impairment (MBI), mild cognitive impairment (MCI), and a psychiatry group (PG) to compare the risk of progression to dementia.

Methods: From 677 initially assessed $\geq 60$-year-old patients, a series of 348 patients was studied for a five-year period until censoring or conversion to dementia: 96 with MBI, 87 with MCI, and 165 with general psychiatry disorders, including 4 subgroups: Anxiety, Depression, Psychosis and Others. All patients were assessed with clinical, psychiatric, neurological, neuropsychological, and neuroimaging studies.

Results: From 348 patients, 126 evolved to dementia (36.2\%). Conversion was significantly higher in MBI (71.5\%), followed by the MCI-MBI overlap (59.6\%) and MCI (37.8\%) groups, compared to PG (13.9\%) (Log-rank $p<0.001)$. MCI patients mostly converted to Alzheimer's dementia, while MBI converted to frontotemporal dementia and Lewy body dementia. Patients in PG converted to Lewy body dementia and frontotemporal dementia.

Conclusion: Conversion to dementia is significantly higher in patients with neuropsychiatric symptoms. The MBI concept generates a new milestone in the refining of diagnosis of neurodegenerative diseases and the possibility of creating neuropsychiatric profiles. Its earlier identification will allow new possibilities for therapeutic intervention.
\end{abstract}

Keywords: Alzheimer's disease, conversion to dementia, follow-up, frontotemporal disease, Lewy body disease, mild behavioral impairment, mild cognitive impairment, pre-dementia

\footnotetext{
$\dagger$ Year of death: 2016.

${ }^{*}$ Correspondence to: Fernando E. Taragano, National Scientific Research Council-CONICET, Buenos Aires, Argentina. Tel.: +54 1152990372 \#6; Fax: +54 114541 3790; E-mail: fernando@ taragano.net.
}

\section{INTRODUCTION}

Even though it is known that neuropsychiatric symptoms (NPS) are common in dementia and are recognized as core to the dementia process by the National Institute on Aging-Alzheimer's Association 
(NIA-AA) [1], they still have not been extensively studied in the pre-dementia stage. The NPS NIA-AA core criteria for all-cause of dementia are described as "changes in personality, behavior, or comportment symptoms that include: uncharacteristic mood fluctuations such as agitation, impaired motivation, impaired initiative, apathy, loss of drive, social withdrawal, decreased interest in previous activities, loss of empathy, compulsive or obsessive behaviors, social unacceptable behaviors" [1].

Instead, in mild cognitive impairment (MCI), those NPS have been more characterized and the presence of apathy, depression, agitation, delusions, hallucinations, and sleep disorders has been associated with an increased risk of progression to dementia [2,3]. With regards to dementia, NPS occur in $80-90 \%$ of patients during the clinical course of the disease and fluctuate over time. But, while these symptoms have been evaluated in cross-sectional studies, longitudinal studies are scarce [4].

Since many years ago, there has been greater awareness of the importance of NPS in dementia due to their high prevalence, the increased caregivers' burden, and the early institutionalization of patients that NPS induce [5-7]. Even more, it has been reported that caregivers' burden is more related to behavioral disorders than to cognitive impairment $[8,9]$ and this burden can be psychological and/or physical and/or economic.

NPS are an important manifestation of the dementia syndrome regardless of the underlying disease, and have a strong correlation with the degree of functional impairment. Taragano \& Allegri (2003) proposed the existence of a syndrome named "Mild Behavioral Impairment" (MBI) [10]; at the International Conference of Alzheimer's Disease (2004), it was suggested that many patients convert to dementia with NPS as the first indicators of the development of a neurodegenerative disease [11]. Later (2008), we published that MBI defines a late life syndrome with prominent psychiatric and related behavioral symptoms in the absence of major cognitive symptoms [12] and demonstrated (2009) that MBI is associated with a greater and faster progression to dementia [13].

\section{Objective}

The aim of our study was to observe and analyze patients with MBI, MCI, and a psychiatric group to compare the risk of progression to dementia.

\section{MATERIALS AND METHODS}

\section{Study population}

A 5-year prospective, longitudinal inception cohort study was carried out with $\geq 60$-year-old patients attending to the Neuropsychiatry Research Unit of CEMIC University Hospital between January 2007 and January 2012.

The neuropsychiatry research unit belongs to the Neurology Section of the Medicine Department of CEMIC University Hospital. The research group was a multidisciplinary team composed by neurologists, psychiatrists, gerontologists, neuropsychologists, and psychologists. Patients were diagnosed with MCI, MBI, or general psychiatry disorders.

\section{Diagnosis}

MBI was defined as a behavioral disturbance not meeting NINCS-ADRDA [14] criteria for Alzheimer's dementia, Lund and Manchester criteria [15] for frontotemporal dementia (FTD), and DLB International Consortium criteria [16] for Lewy body dementia (DLB). Additionally, patients must not also meet the DSM-IV criteria [17] for psychosis or another major psychiatric condition.

\section{MBI inclusion criteria}

a) Accept to participate in the study and signed inform consent; $b$ ) Patients $\geq 60$ years old; c) Presence of a major change in patient behavior this change occurring later in life $(\geq 60)$ that is persistent $(\geq 6$ months); d) No complaint of cognitive impairment by patient/informant; e) Normal occupational and social functioning; f) Normal activities of daily living; g) Absence of dementia.

Major persistent changes in patient behavior that might have led to a diagnosis of MBI are as follows: agitation, anxiety symptoms, apathy, aspontaneity, delusion symptoms, depressive symptoms, disinhibition, emotional lability, euphoria, impulsivity, indifference, irritability, lack of empathy, loss of insight, loss of personal hygiene, loss of social tact, oral/dietary changes, perseverant behavior, sleep disorders.

A patient with major persistent change in behavior but no cognitive complaints from either the patient or the caregiver was considered to have MBI regardless of whether cognitive impairment was subsequently found on testing or not. 
MBI exclusion criteria

a) Patients $<60$ years old; b) Impaired daily activities; c) Presence of Alzheimer's dementia [14]; d) Presence of FTD [15]; e) Presence of LBD [16]; f) Presence of another concomitant neurological or psychiatric disorder that could better explain disturbances (i.e., epilepsy, major stroke, tumors, schizophrenia, etc.); g) Behavioral disturbances of acute onset; h) Alcohol or substance abuse.

MCI was defined as a cognitive decline meeting Petersen et al MCI criteria [18].

\section{MCI inclusion criteria}

a) Accept study participation and signed informed consent; b) Age $\geq 60$ years old; c) Memory complaint or other cognitive complaint; d) Normal activities of daily living; e) Normal general cognitive function; f) Abnormal memory or other abnormal cognitive functions for age; g) Not demented.

Abnormal memory or other abnormal cognitive functions for age were defined as a score on a neuropsychological standardized test $1.5 \mathrm{SD}$ below the mean compared with individuals of the same age and level of education.

A patient with cognitive complaints and psychiatric symptoms was considered to have MCI regardless of whether NPS were subsequently found on testing or not.

\section{MCI exclusion criteria}

a) Age $<60$ years old; b) Impaired daily activities; c) Presence of Alzheimer's dementia [14]; d) Presence of FTD [15]; e) Presence of LBD [16]; f) Presence of another concomitant neurological or psychiatric disorder that could better explain the cognitive symptoms (i.e., epilepsy, major stroke, tumors, schizophrenia, etc.); g) Acute cognitive disturbances; h) Alcohol or substance abuse.

\section{The psychiatric group}

In 2009, we demonstrated that MBI is associated with a higher risk for dementia compared to MCI. In the present study, we aim to verify if the risk of conversion to dementia of the MBI group is different from those patients with general psychiatric disorders (PG).

Psychiatric illnesses were diagnosed according to DSM-IV diagnostic criteria [17]. A complete semi structured neuropsychiatric interview was performed and neuropsychiatric general and focused scales were used.
The following inclusion criteria were applied to define the PG:

\section{Inclusion criteria for the psychiatric group}

Age $\geq 60$ years old; Patients with general psychiatric disorders meeting DSM-IV diagnostic criteria for major depression disorder (MDD), generalized anxiety disorder (GAD), schizoaffective disorder (SZD), personality disorder, post-traumatic stress disorder (PTSD), bipolar disorder type I and II (BPD I and BPD II); Patients without suspected or reported dementia; If a patient had cognitive symptoms, a responsible family member or informant should ensure that they were not the first symptoms of the psychiatric illness.

\section{Exclusion criteria for the psychiatric group}

Age $<60$ years old; Impaired daily activities; Presence of Alzheimer's dementia [14]; Presence of FTD [15]; Presence of LBD [16]; Other neurological problem or psychiatric disorder that could better explain the behavioral symptoms (e.g., epilepsy, tumors, schizophrenia); Acute behavioral disturbances; Alcohol or substance abuse.

\section{Screening procedure}

All of the recruited patients signed a written informed consent after they were given a full explanation of the study. The research was performed in accordance with the ICH Good Clinical Practice guidelines, the latest revision of the 1964 Helsinki Declaration (last amended in Seoul 2008), and the Buenos Aires Government Health Authorities regulations.

Patients were assessed using a semi-structured neuropsychiatric interview and were examined at least every 6 months or when necessary. At each visit conversion to dementia was assessed.

Physical examinations and laboratory analysis were performed at baseline and whenever was needed as it is done in usual care.

Vascular risk factors and co-morbidities such as body mass index $>30$, high blood pressure, high blood cholesterol levels, cigarette smoking, diabetes, sedentary lifestyle, hypothyroidism and coronary heart disease were assessed.

Two scales were used to assess psychiatric symptoms, the Beck Depression Scale [19] and The Neuropsychiatric Inventory (NPI) [20].

An extensive neuropsychological battery to evaluate cognitive ability was administered to each patient: 
Mini-Mental State Examination (MMSE) [21], Digit span [22], Trail making test "A\&B" [23], Boston naming test [24], Semantic and Verbal fluency [25], Signoret memory battery [26], and Wechsler Scale of Intelligence [27].

\section{Methodology used to screen for conversion to dementia}

Clinical Dementia Rating Scale (CDR) was used to evaluate the stage of cognitive impairment and dementia [28, 29]. CDR from 0,5 to 1 : When a subject convert from the CDR- 0.5 score to CDR- 1 , it was considered a significant clinical milestone in the progression of the disease and was interpreted as the conversion from mild deterioration stage to dementia stage.

Structural imaging (Brain CT scan or MRI) was performed at baseline to all participants for diagnostic purpose.

Functional brain imaging $\left(\mathrm{Tc}^{99} \mathrm{SPECT}\right.$ or FDG ${ }^{18}$ PET-CT) was performed only for research purposes and it was planned to be obtained from at least $30 \%$ of participants.

\section{Statistical analysis}

Variables from patients grouped within MBI, MCI, and PG were compared. Categorical variables were expressed as percentages. For continuous variables, the mean and standard deviations were estimated. For the non-normal distributed variables, the median and percentiles were considered.

Differences in the frequency of distribution were compared using univariate $\chi$ tests. Student's $t$ test was used to compare groups with continuous variables, while non-parametric Mann-WhitneyWilcoxon and Kruskall-Wallis tests were used to compare groups with non-normal distributed variables. Kaplan-Meier curves for survival analysis were used to analyze the time from evolution to dementia.

The follow-up period for each patient was from baseline visit to the evolution to dementia, censoring or exclusion from the study. MannWhitney-Wilcoxon $U$ test and Cox proportional models were also used to analyze associations between multiple explanatory variables and conversion to dementia. The effects are shown as risk indices with $95 \%$ confidence interval. Stata 8.0 software was used for all statistical analyses (StataCorp LP, College Station, Tex.).

\section{RESULTS}

\section{Study population}

Six hundred and seventy-seven $\geq 60$-year-old patients were initially assessed. Patients with preexisting dementia were excluded $(n=210)$, while other 74 patients did not attend to follow up visits. Patients with cognitive or behavioral symptoms not attributable to a specific psychiatric disorder $(n=203)$ were included: $87 \mathrm{MCI}, 96 \mathrm{MBI}$, and 20 lost follow up. The PG included 190 patients with specific psychiatric disorders: 165 completed the study and 25 were lost in follow up.

Total study sample consisted of 348 patients.

\section{Conformation of the psychiatric group}

The PG was divided in four subtypes of psychiatric domains: Anxiety (GAD), $n=33$; Depression (MDD), $n=66$; Psychosis (SZD), $n=31$; and Others (personality disorder, PTSD, BPD I, and BPD II), $n=35$.

\section{Demographic data}

Demographic data is depicted in Table 1. Considered variables showed no statistical differences between groups.

\section{Clinical characteristics}

\section{Family background of dementia}

Statistical differences were found between MCI, MBI, and PG groups (PG: $\chi^{2}=19.0, \mathrm{df}=2, p<0.001$; Table 2).

\section{Neurological exam}

The distribution of pyramidal, extrapyramidal signs, and archaic reflexes was heterogeneous $\left(\chi^{2}=75.3, \mathrm{df}=6, p<0.001\right)$ showing a greater frequency of these symptoms in MBI patients (Table 2).

\section{Psychopharmacological treatment}

The prescription of psychopharmacological drugs was heterogeneous between groups $\left(\chi^{2}=42, \mathrm{df}=8\right.$, $p<0.001$ ), with the PG group showing the highest prescription of these drugs, followed by the MBI group (Table 2). 
Table 1

Patients' demographic characteristics at initial visit assessment

\begin{tabular}{|c|c|c|c|c|}
\hline Variable & $\begin{array}{c}\text { MCI } \\
n=87\end{array}$ & $\begin{array}{c}\text { MBI } \\
n=96\end{array}$ & $\begin{array}{c}\text { Psychiatric group } \\
n=165(\%)\end{array}$ & $p$ value \\
\hline$\overline{\text { Age, mean (SD) }}$ & $71.1(7.7)$ & $71.9(8.9)$ & $70.8(7.5)$ & $p=0.54^{*}$ \\
\hline \multicolumn{5}{|l|}{ Gender } \\
\hline Female, $n(\%)$ & $53(61)$ & $52(55)$ & $81(51)$ & $\chi^{2}=3.23, \mathrm{df}=2, p=0.199^{\dagger}$ \\
\hline \multicolumn{5}{|l|}{ Civil status, $n(\%)$} \\
\hline Married & $57(65.5)$ & $67(69.8)$ & $112(67.9)$ & $\chi^{2}=2.41, \mathrm{df}=6, p=0.878^{\dagger}$ \\
\hline Single & $5(5.7)$ & $4(4.2)$ & $8(4.8)$ & \\
\hline Divorced & $5(5.7)$ & $8(8.3)$ & $16(9.7)$ & \\
\hline Widowed & $20(23)$ & $17(17.7)$ & $29(17.6)$ & \\
\hline \multicolumn{5}{|l|}{ Years of education } \\
\hline Median & 12.1 & 12 & 13.7 & $p=0.229 *$ \\
\hline Under 9 years, $n(\%)$ & $15(17.2)$ & $21(21.8)$ & $29(17.6)$ & $\chi^{2}=0.896, \mathrm{df}=2, p=0.639^{\dagger}$ \\
\hline \multicolumn{5}{|l|}{ Job occupation, $n(\%)$} \\
\hline Retired & $70(80.5)$ & $74(77.1)$ & $115(69.7)$ & $\chi^{2}=3.96, \mathrm{df}=2, p=0.138^{\dagger}$ \\
\hline Active & $17(19.5)$ & $22(22.9)$ & $50(30.3)$ & \\
\hline Months of follow up & & & & $p<0.001^{*}$ \\
\hline Median & 42 & 32 & 35 & \\
\hline Percentile 10 & 13 & 11 & 11 & \\
\hline Percentile 90 & 52 & 60 & 57 & \\
\hline Number of visits & & & & $p<0.006^{*}$ \\
\hline Median & 7 & 10 & 6 & \\
\hline Percentile 10 & 2 & 5 & 3 & \\
\hline Percentile 90 & 21 & 23 & 12 & \\
\hline
\end{tabular}

${ }^{*}$ Kruskal - Wallis test; ${ }^{\dagger}$ Pearson $\chi^{2}$.

Table 2

Clinical characteristics at initial visit assessment

\begin{tabular}{|c|c|c|c|c|}
\hline Variable & $\begin{array}{r}\text { MCI } \\
n=87(\%)\end{array}$ & $\begin{array}{r}\text { MBI } \\
n=96(\%)\end{array}$ & $\begin{array}{l}\text { Psychiatric group } \\
n=165(\%)\end{array}$ & $p$ value \\
\hline Family background of dementia & $16(18.3)$ & $25(26)$ & $11(6.6)$ & $\chi^{2}=19.0, \mathrm{df}=2, p<0.001^{*}$ \\
\hline \multicolumn{5}{|l|}{ Neurological exam } \\
\hline Pyramidal signs & $8(9.1)$ & $26(21.8)$ & $18(11)$ & \multirow[t]{3}{*}{$\chi^{2}=75.3, \mathrm{df}=6, p<0.001^{*}$} \\
\hline Extrapyramidal signs & $22(9.2)$ & $36(37.5)$ & $20(12.1)$ & \\
\hline Archaic reflexes & $10(11.4)$ & $45(46.8)$ & $28(16.9)$ & \\
\hline \multicolumn{5}{|l|}{ Psychopharmacological treatment } \\
\hline Antidepressants & $7(8)$ & $10(10.4)$ & $53(32.2)$ & \multirow[t]{4}{*}{$\chi^{2}=42, \mathrm{df}=8, p<0.001^{*}$} \\
\hline Antipsychotics & $5(5.7)$ & $20(20.8)$ & $31(18.8)$ & \\
\hline Benzodiazepines & $29(33.3)$ & $29(30.2)$ & $30(18.1)$ & \\
\hline Others & $10(11.4)$ & $21(21.8)$ & $25(15.1)$ & \\
\hline
\end{tabular}

${ }^{*}$ Pearson $\chi^{2}$. Archaic reflexes were considered as PRESENT or ABSENT. PRESENT was defined when the patient had one or more of the following reflexes: suck, snout, palmomental, and grasp reflexes, even though if they were found in a mild presentation.

\section{Vascular risk factors and co-morbidities}

Significant differences were found between groups in the following variables: $\mathrm{BMI} \geq 30$ $(p=0.046)$, coronary heart disease $(p=0.028)$, diabetes $(p=0.044)$, sedentary lifestyle $(p=0.001)$, and dyslipidemia $(p=0.043)$. On the other hand, there were no significant differences in number of comorbidities $(p=0.95)$. More detailed description about these data is out of the scope of this paper.

\section{Behavioral symptoms}

Behavioral symptoms were found in almost a quarter of MCI patients (Table 3). Irritability, disinhibition, and delusions followed by nighttime behaviors, depression, and apathy were the predominant symptoms in MBI group while anxiety, irritability, and nighttime behaviors were the predominant symptoms in MCI group. No differences between MCI and MBI groups were observed in scores of Beck Depression Inventory.

\section{Cognitive symptoms}

Memory impairment symptoms were found in more than a quarter of MBI patients (27.1\%) as shown in Table 4. 
Table 3

Neuropsychiatric symptoms in MCI and MBI patients at initial assessment

\begin{tabular}{lccc}
\hline & $\begin{array}{c}\text { MCI } 87 \\
n(\%)\end{array}$ & $\begin{array}{c}\text { MBI } 96 \\
n(\%)\end{array}$ & $p$ value \\
\hline $\begin{array}{l}\text { Subjects with behavioral changes } \\
\quad \text { assessed through NPI }\end{array}$ & $21(24.1)$ & $96(100)$ & $\chi^{2}=114, \mathrm{df}=1, p<0.0001^{*}$ \\
Neuropsychiatric symptom: & & & \\
Delusions & $5(5.7)$ & $50(52.0)$ & $\chi^{2}=46.6, \mathrm{df}=1, p<0.0001^{\dagger}$ \\
Hallucinations & $4(4.5)$ & $21(21.8)$ & $\chi^{2}=11.6, \mathrm{df}=1, p<0.001^{\dagger}$ \\
Agitation/Aggression & $7(8.0)$ & $25(26.0)$ & $\chi^{2}=10.2, \mathrm{df}=1, p<0.001^{*}$ \\
Depression/Dysphoria & $9(10.3)$ & $28(29.1)$ & $\chi^{2}=10.0, \mathrm{df}=1, p<0.002^{*}$ \\
Anxiety & $19(21.8)$ & $39(40.6)$ & $\chi^{2}=7.44, \mathrm{df}=1, p<0.007^{*}$ \\
Elation/Euphoria & $3(3.4)$ & $9(9.3)$ & $\chi^{2}=5.39, \mathrm{df}=1, p<0.020^{\dagger}$ \\
Apathy/Indifference & $9(10.3)$ & $27(28.1)$ & $\chi^{2}=5.97, \mathrm{df}=1, p<0.015^{*}$ \\
Disinhibition & $9(10.3)$ & $50(52.0)$ & $\chi^{2}=24.7, \mathrm{df}=1, p<0.001^{*}$ \\
Irritability/Lability & $12(13.7)$ & $52(54.1)$ & $\chi^{2}=31.4, \mathrm{df}=1, p<0.001^{*}$ \\
Aberrant Motor Disturbance & $5(5.7)$ & $24(25.0)$ & $\chi^{2}=21.9, \mathrm{df}=1, p<0.001^{\dagger}$ \\
Nighttime Behaviors & $12(13.7)$ & $44(45.8)$ & $\chi^{2}=22.1, \mathrm{df}=1, p<0.001^{*}$ \\
Appetite/Eating & $7(8.0)$ & $24(25.0)$ & $\chi^{2}=14.6, \mathrm{df}=1, p<0.001^{*}$ \\
Subjects with depressive symptoms & & & \\
$\quad$ assessed through BDI & & & \\
Mean (SD) & $7.4(2.8)$ & $8.9(2.4)$ & $\mathrm{z}=0.476 p=0.565^{\ddagger}$ \\
Score $\geq 10 n$ (\%) & $7(8.0)$ & $12(12.5)$ & $\chi^{2}=0.973, \mathrm{df}=1, p=0.32^{*}$ \\
\hline
\end{tabular}

${ }^{*}$ Pearson $\chi^{2}$; ${ }^{\dagger}$ Fisherexact; ${ }^{\ddagger}$ Wilcoxon Rank sum test; NPI, Neuropsychiatric Inventory; BDI, Beck Depression Inventory.

Table 4

Cognitive profile in MCI and MBI patients at initial assessment

\begin{tabular}{|c|c|c|c|}
\hline & MCI & MBI & $p$ value \\
\hline Total subjects in group, $n(\%)$ & $87(100)$ & $96(100)$ & \\
\hline \multicolumn{4}{|l|}{ Memory } \\
\hline Memory impairment, $n(\%)$ & $87(100)$ & $26(27.1)$ & $\chi^{2}=103, \mathrm{df}=1, p<0.001^{*}$ \\
\hline Immediate recall, median & 7 & 6 & $z=-7.064$ Prob $>|z|=0.000^{\dagger}$ \\
\hline Delayed Recall, median & 6 & 5 & $z=-3.781$ Prob $>|z|=0.000^{\dagger}$ \\
\hline Verbal serial learning, median & 6 & 7 & $z=-5.099$ Prob $>|z|=0.000^{\dagger}$ \\
\hline Delayed serial memory, median & 4 & 6 & $\mathrm{z}=-5.305$ Prob $>|z|=0.000^{\dagger}$ \\
\hline Cued verbal recall, median & 6 & 7 & $z=-1.607$ Prob $>|z|=0.108^{\dagger}$ \\
\hline Recognition, median & 10 & 9 & $\mathrm{z}=2.790$ Prob $>|z|=0.005^{\dagger}$ \\
\hline Intrusions, $n$ & 30 & 45 & $\chi^{2}=2.9 \mathrm{df}=1, p=0.089^{*}$ \\
\hline Total MMSE mean (SD) & $27.9(0.17)$ & $26.9(0.33)$ & $t=4.420 P>|\mathrm{t}|=0.000^{\ddagger}$ \\
\hline \multicolumn{4}{|l|}{ Naming } \\
\hline Boston Naming Test, mean (SD) & $48.1(0.44)$ & $46.5(0.55)$ & $t=2.2663 P>|\mathrm{t}|=0.024^{\ddagger}$ \\
\hline \multicolumn{4}{|l|}{ Fluency } \\
\hline Semantic fluency, median & 14 & 15 & $\mathrm{z}=2.169 \operatorname{Prob}>|\mathrm{z}|=0.030^{\dagger}$ \\
\hline Phonological fluency, median & 12 & 11 & $z=0.433 \operatorname{Prob}>|z|=0.665^{\dagger}$ \\
\hline \multicolumn{4}{|l|}{ Attention } \\
\hline Direct DigitSpan, median & 7 & 6 & $\mathrm{z}=6.760 \operatorname{Prob}>|\mathrm{z}|=0.000^{\dagger}$ \\
\hline Reverse DigitSpan, median & 5 & 5 & $\mathrm{z}=4.860 \operatorname{Prob}>|\mathrm{z}|=0.601^{\dagger}$ \\
\hline \multicolumn{4}{|l|}{ Sequencing } \\
\hline TrailMaking Test B, mean (SD) & $114(7.7)$ & $165(6.9)$ & $t=-2.616 P>|\mathrm{t}|=0.009^{\ddagger}$ \\
\hline \multicolumn{4}{|l|}{ Intelligences } \\
\hline Vocabulary, median & 53 & 47 & $\mathrm{z}=-0.359 \operatorname{Prob}>|\mathrm{z}|=0.719^{\dagger}$ \\
\hline Analogies, median & 47 & 38 & $\mathrm{z}=-0.341$ Prob $>|z|=0.519^{\dagger}$ \\
\hline Block design, median & 43 & 31 & $z=-4.309$ Prob $>|z|=0.719^{\dagger}$ \\
\hline Matrices, median & 41 & 35 & $\mathrm{z}=-3.508$ Prob $>|\mathrm{z}|=0.719^{\dagger}$ \\
\hline Verbal IQ, mean (SD) & $104.7(1.3)$ & $102.1(1.1)$ & $t=4.2665, p<0.001^{\ddagger}$ \\
\hline Performance IQ, mean(SD) & $97.7(1.5)$ & $86.2(1.2)$ & $t=4.3675, p<0.001^{\ddagger}$ \\
\hline Global IQ, mean(SD) & $101.2(0.8)$ & $94.1(15.0)$ & $t=6.2608, p<0.001^{\ddagger}$ \\
\hline
\end{tabular}

${ }^{*}$ Pearson $\chi^{2} ;{ }^{\dagger}$ Wilcoxon Rank sum test; ${ }^{\ddagger} t$-test; MMSE, Mini-Mental State Examination. 
Table 5

Neuroimage findings in MCI and MBI patients

\begin{tabular}{lccc}
\hline MRI and CT scan & MCI & MBI & $p$ value \\
& $n=87(\%)$ & $n=96(\%)$ & \\
\hline General atrophy & $5(5.7)$ & $4(4.2)$ & $\chi^{2}=2.44, \mathrm{df}=1, p=0.621^{\dagger}$ \\
Leukoaraiosis & $18(20,6)$ & $20(20,8)$ & $\chi^{2}=0,57, \mathrm{df}=1, p=0.981^{*}$ \\
Focal atrophy & $3(3.4)$ & $4(4.2)$ & $\chi^{2}=0.640, \mathrm{df}=1, p=0.800^{\dagger}$ \\
\hline
\end{tabular}

*Pearson $\chi^{2} ;{ }^{\dagger}$ Fisher Exact test.

Significant differences were observed in language; verbal, executive and global IQ; attention; executive functions; and total MMSE between MCI and MBI groups (Table 4).

\section{Neuroimaging findings}

There were no significant differences $(p>0.05)$ between MCI and MBI groups in patients with underling vascular disease, atrophy (focal and general) (Table 5).

\section{Conversion to dementia}

During the five-year follow-up period, from the total 348 patients, more than a third part $(36.2 \%$, $n=126$ ) converted to dementia. A higher proportion of the suspected pre-dementia patients (MBI plus $\mathrm{MCI})$ converted to dementia $(56.3 \%, n=103)$ with a cumulative yearly rate of conversion of $10.0 \%$ for the first year, $29.0 \%$ for the second year, $45.5 \%$ for the third year, $50.0 \%$ for the fourth year, and $56.3 \%$, finally, for the fifth year. In terms of Kaplan-Meyer analysis, as a result of the converted cases, the survival curve (free of dementia) was higher in the PG $\left(\chi^{2}=40.2, \mathrm{df}=3, p<0.001\right.$; Fig. 1$)$.

Frequency of conversion to dementia was: MBI group $69.7 \%(n=67)$; MCI group $41.3 \%(n=36)$; and PG $13.9 \%(n=23)$.

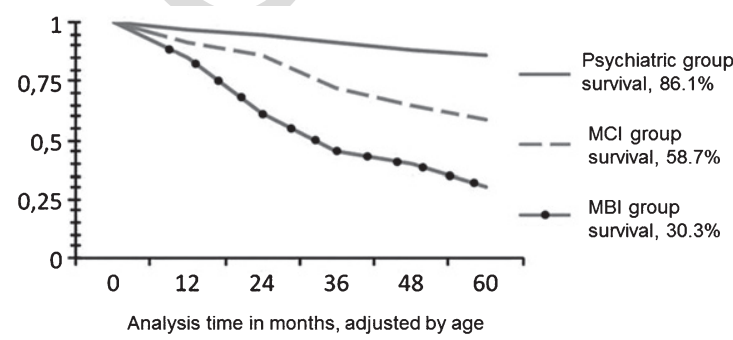

Fig. 1. Kaplan-Meier estimate survival by diagnosis: psychiatric group, mild cognitive impairment (MCI), and mild behavioral impairment (MBI). Log-Rank test for the comparison of survival curves upon time, adjusted by age: $\chi^{2}=40.2, \mathrm{df}=3, p<0.001$.
According to different degenerative diseases, conversion to dementia was: Alzheimer's dementia (NINCS-ADRDA criteria [14]): in MCI 83.3\% $(n=30)$, MBI 26.8\% $(n=18)$, and PG $21.7 \%(n=5)$; FTD (Lund and Manchester criteria [15]): in MCI $16.6 \%(n=6)$, MBI $44.7 \%(n=30)$, and PG $30.4 \%$ $(n=7)$; and DLB (DLB International Consortium criteria [16]): in MCI 0\%, MBI 28.3\% $(n=19)$, and PG $47.8 \%(n=11)$.

Frequency of conversion to different type of degenerative dementia in each studied group showed a heterogeneous distribution between them $\left(\chi^{2}=129\right.$, $\mathrm{df}=6 p<0.001$ ).

According to different subtypes of psychiatric domains, conversion to dementia was: Anxiety $9.1 \%$ $(n=3)$; Depression $15.2 \%(n=10)$; Psychosis $25.8 \%$ $(n=8)$; and Others $5.7 \%(n=2)$

Results showed that the distribution of cases that converted to dementia was homogeneous among considered PG subgroups ( $p=0.096)$.

Due to the frequency of NPS in MCI (24.1\%), the MCI group was divided in two subgroups: with and without NPS. MCI with NPS symptoms group was defined when at least 1 (one) or more NPS of any domain were found in the NPI. Frequency of conversion to dementia in MCI-with NPS was $52.4 \%$ while in MCI-without NPS was $37.8 \%$ (Fig. 2).

Figure 2 displays Kaplan-Meier analysis adjusted for age showing significant differences between all survival curves as the result of conversion to dementia cases.

Due to the frequency of cognitive symptoms ( $\mathrm{CogS}$ ) found in MBI (27.1\%), the MBI group was divided in two subgroups: with and without CogS. MBI with $\operatorname{CogS}$ were considered as patients presenting cognitive impairment of more than 1.5 SD in the neuropsychological tests performed after they were included in MBI group. Frequency of conversion to dementia in MBI-with $\operatorname{CogS}$ was $65.4 \%$ while in MBI-without CogS was $71.5 \%$ (Fig. 3).

Assuming that MCI with NPS and MBI with CogS could represent the same group or, at least, they should overlap significantly, we regrouped the 


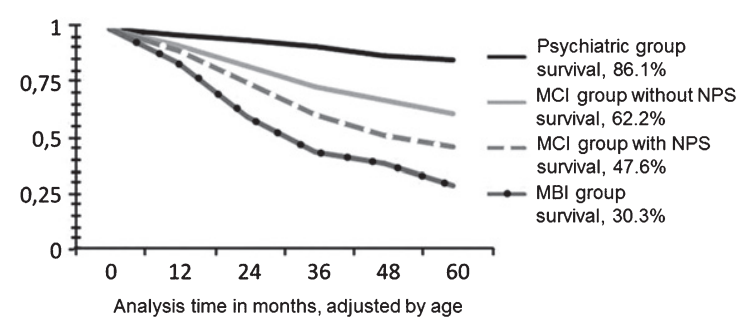

Fig. 2. Kaplan-Meier estimate survival by diagnosis: Psychiatric, mild cognitive impairment (MCI) with and without neuropsychiatric symptoms (NPS), and mild behavioral impairment (MBI) groups. Log-Rank test for the comparison of survival curves upon time, adjusted by age: $\chi^{2}=40.78, \mathrm{df}=3, p<0.001$.

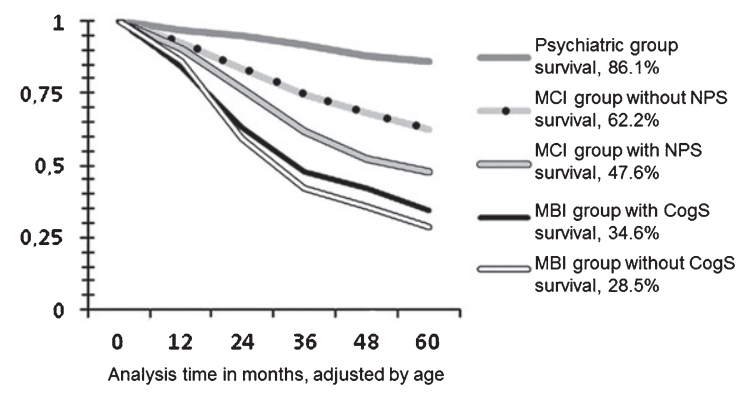

Fig. 3. Kaplan-Meier estimate survival by diagnosis: psychiatric group, mild cognitive impairment (MCI) with and without neuropsychiatric symptoms (NPS), and mild behavioral impairment (MBI) with and without cognitive symptoms (CogS). Log-Rank test for the comparison of survival curves upon time, adjusted by age: $\chi^{2}=40.78, \mathrm{df}=3, p<0.001$.

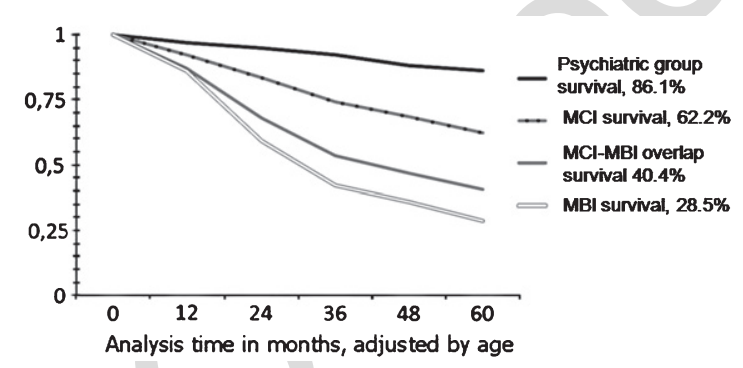

Fig. 4. Kaplan-Meier estimate survival by diagnosis: psychiatric group, mild cognitive impairment (MCI), MCI-MBI overlap group, and mild behavioral impairment (MBI). Log-Rank test for the comparison of survival curves upon time, adjusted by age: $\chi^{2}=40.78, \mathrm{df}=3, p<0.001$.

patients in the following way: MCI, overlapping group (MCI-MBI), MBI, and PG. In this new analysis, we gathered both MCI patients with NPS and MBI patients with cognitive objective impairment: this new group is defined as the MCI-MBI overlap group (Fig. 4).

Initial diagnosis and conversion to different types of dementia is depicted in Table 6.

\section{DISCUSSION}

It has long been recognized that behavioral symptoms might be an early manifestation of dementia. In 2003, the International Statistical Classification of Diseases and Related Health Problems (WHO) stated “... the impairments of cognitive function are commonly accompanied and occasionally preceded by deterioration in emotional control, social behavior, or motivation ... [30]".

Since then we have been investigating behavioral changes in elderly patients and their relationship with the development of different types of dementia and, within this context, the concept of MBI was developed as a potential pre-dementia construct.

Identifying an MBI population is a novel approach to study prevention strategies, with the hypothesis that early identification and treatment of behavioral symptoms in neurodegenerative illness could slow or mitigate the presentation of psychiatric complications of dementia. Moreover, the MBI concept may allow current medication or future disease modifying agents to be used earlier in the course of the disease. However, since there is an increased international interest in the MBI concept, as suggested by other authors, it is necessary to be aware of the potential increase of over-diagnosis because of the current lack of evidence showing specific advantages from identifying and targeting MBI [31].

In early 2016, the Alzheimer's Association International Society to Advance Alzheimer's Research and Treatment (ISTAART) stated that it was necessary to develop a specifically designed scale for MBI to accurately estimate prevalence and as a later outcome, allow the measurement of preventive therapies [32].

Therefore, ISTAART made explicit the definition of MBI and its differences with MCI. Firstly, the ISTAART MBI criteria requires changes in behavior or personality observed by patient, informant, or clinician, starting later in life (age $\geq 50$ years) and persisting at least intermittently for $\geq 6$ months. Secondly, behaviors are of sufficient severity to produce at least minimal impairment. Thirdly, the impairment in social, occupational, or interpersonal function must be attributable to NPS such as changes in personality and behavior, and not to cognitive decline. Finally, if MBI is diagnosed concurrently with MCI, the functional impairment must be attributed to behavior or personality changes, and not the cognitive impairments, although this may be difficult to ascertain at times. The ISTAART NPS recommends the 
Table 6

Initial diagnosis and conversion to different types of dementia

\begin{tabular}{|c|c|c|c|c|c|c|c|}
\hline \multirow[b]{3}{*}{$\begin{array}{l}\text { Type of } \\
\text { dementia, } n(\%)\end{array}$} & \multicolumn{7}{|c|}{ Initial Diagnosis } \\
\hline & \multicolumn{7}{|c|}{ Psychiatric illnesses subgroups } \\
\hline & $\begin{array}{c}\text { MBI } \\
n=96\end{array}$ & $\begin{array}{c}\text { MCI } \\
n=87\end{array}$ & $\begin{array}{c}\text { Depression } \\
n=66\end{array}$ & $\begin{array}{c}\text { Psychosis } \\
n=31\end{array}$ & $\begin{array}{c}\text { Anxiety } \\
n=33\end{array}$ & $\begin{array}{l}\text { Other } \\
n=35\end{array}$ & $\begin{array}{c}\text { Total } \\
n=348\end{array}$ \\
\hline Alzheimer's & $18(18.75)$ & $30(34.48)$ & $4(6.06)$ & $2(6.45)$ & $1(3.03)$ & $1(2.85)$ & $56(44.4)$ \\
\hline Frontotemporal & $30(31.25)$ & $6(6.89)$ & $2(3.03)$ & $3(9.67)$ & $1(3.03)$ & $0(0.00)$ & $42(33.3)$ \\
\hline Lewy body & $19(19.79)$ & $0(0.00)$ & $4(6.06)$ & $3(9.67)$ & $1(3.03)$ & $1(2.85)$ & $28(22.2)$ \\
\hline Total n $(\%)$ & $67(53.2)$ & $36(28.6)$ & $10(7.9)$ & $8(6.3)$ & $3(2.4)$ & $2(1.6)$ & $126(36.20)$ \\
\hline
\end{tabular}

Pearson $\chi^{2}=132$, df $=15, p<0.0001$.

use of the NIA-AA consensus criteria for MCI and dementia.

Later, the ISTAART expanded on the description of behavioral changes dividing them into five subcategories: motivation, affect, impulse control, social appropriateness, and perception/thought content. MBI subcategories may be correlated with NPI symptoms as follow: decreased motivation (NPI: apathy/ indifference); affective dysregulation (NPI: depression/dysphoria, anxiety, elation/euphoria, and irritability); impulse dyscontrol (NPI: agitation/aggression, aberrant motor behavior, and appetite/eating behavior); social inappropriateness (NPI: disinhibition); and abnormal perception/thought content (NPI: delusions and hallucinations).

In accordance with this recommendation, a first scale to measure MBI symptoms has recently been published [33]. The standardization of the assessment of MBI will help to define a target population for new treatment research or potential greater efficacy of older treatments.

In the present study, and as far as we know for the first time in the dementia knowledge field, research was conducted to analyze MBI and MCI patients as well as a psychiatric group (PG) in order to compare their risk of progression to dementia. We followed up 348 patients for a period of five years: 183 suspected of pre-dementia (MCI and MBI) and 165 patients with recognized general psychiatric disorders.

Among considered co-morbidities, significant differences were found between groups. This finding might have importance as there are studies suggesting that, in higher income countries, the incidence of dementia has decreased due to prevention strategies and social changes such as improvement in education and better control of modifiable risk factors [34-36].

Concerning family background, the MBI group was the one who had the highest family history of dementia. Our hypothesis is that MBI patients tend to convert more frequently to FTD and, therefore, they could have more significant family background. On a genetic basis, this could be explained by the fact that approximately 1 to $5 \%$ of Alzheimer's disease (AD) patients could be a consequence of dominant autosomal mutations [37] and, although most cases of FTD are sporadic, $20 \%$ to $40 \%$ have been described as relatives, most of them presenting an autosomal dominant pattern $[38,39]$.

Differences found in the neurological exam between groups demonstrate that the MBI group had more neurological signs (pyramidal signs, extrapyramidal signs, and archaic reflexes). Extrapyramidal signs could be explained by pharmacological adverse events, since this group, as it is depicted in Table 2, is the one who significantly used more psychopharmacological medication. Moreover, and regarding all neurological signs, the MBI group presented significant global functional abnormalities and frontal lobe abnormalities in SPECT and PET neuroimages when compared to the other groups. However, there were no significant differences between the MCI and MBI groups with underling vascular disease, and anatomical neuroimaging findings (MRI and CT scan). This matter is not further developed as it is beyond the scope of this paper.

Regarding NPS symptoms, we found that irritability, disinhibition, and delusions followed by depression and apathy were the predominant symptoms in the MBI group, while anxiety and irritability were the most frequent in MCI group.

There are many research studies describing behavioral symptoms of mild type (mostly depressive) associated with MCI [2, 3, 40-43]. The results observed in Beck Depression Inventory in both groups (MCI, MBI) could be related to the fact that this self-administered questionnaire emphasizes more of the cognitive component of depression (decision making, work performance, fatigue/slowing down), since the symptoms of this sphere represent around $50 \%$ of the total score of the questionnaire. 
Mortby et al. in a recent publication observed that a number of co-morbid NPS in MCI patients and not symptom clusters were associated with increased risk of dementia [44]. These findings highlight the importance of NPS and the need for clinicians to consider the presence of NPS in cognitively normal subjects as a possible risk state.

According to the five subcategories described by the ISTAART about behavioral changes, the symptoms we registered in the MBI group could be related to the following subcategories: affective dysregulation (irritability and depression), impulse control (disinhibition), abnormal perception/thought content (delusions), and decreased motivation (apathy). In the MCI group, observed symptoms (anxiety and irritability) could be classified as affective dysregulation according to the ISTAART criteria.

Although the MBI group included patients with 'no complaint of cognitive impairment' by patient/informant, the MBI group had worst cognitive performance in some cognitive domains than the MCI group (for example in MMSE). This might reflect that MBI patients have no awareness and/or perception of their cognitive impairments.

Concerning cognitive symptoms in $\mathrm{MCI}$ and $\mathrm{MBI}$ groups, $\mathrm{MCI}$ is worse on memory impairment while MBI patients with cognitive symptoms performed worse on language domain [Boston Naming Test $(p=0.024)$ and executive domain (Trail Making B test)].

With regards to the worst performance of MBI patients in the language domain (Boston naming test), one of our hypothesis is that as MBI patients tend to convert in a higher proportion to FTD, some of the cases of FTD could correspond to language variants such as semantic primary progressive aphasia (svPPA). As a recent research study demonstrated that both at baseline and follow-up, svPPA patients exhibited significantly more behavioral disturbances of the type characteristic of behavioral FTD compared with other PPA variants [45].

Moreover, we conducted a research study in PPA patients in 2010 where we observed that patients with PPA may suffer behavioral alterations like apathy, anxiety, and depression, and we wondered if these symptoms could be part of diagnostic criteria of this disorder [46].

Our second hypothesis is that this impairment in language tests in MBI patients could correspond to atypical presentations of $\mathrm{AD}$. Cases of PPA, like semantic dementia with the initial complaint of for- getfulness can be diagnosed as AD [47]. Agrammatic, logopenic, and semantic subtypes, each reflecting a characteristic pattern of language impairment and corresponding anatomical distribution of cortical atrophy, represent the most frequent presentations of PPA. The underlying neuropathology of PPA is, most commonly, frontotemporal lobar degeneration in the agrammatic and semantic forms, while in $\mathrm{AD}$, the logopenic form is the most frequent. $\mathrm{AD}$ pathology often displays atypical and asymmetrical anatomical features consistent with the aphasic phenotype [48].

Concerning MBI, worst performance in executive functions; as Cummings and colleagues demonstrated (2004), a high percentage of patients (64\%) with $\mathrm{AD}$ presented with executive dysfunctional disorder. These performed worse on tests of cognition, dementia severity, and activities of daily living. They also had more frequent symptoms of psychosis at baseline compared with patients with normal executive function [49].

From our total patients, $36.2 \%$ converted to dementia. Conversion was significantly higher in MBI $71.5 \%$ followed by the MCI-MBI overlap group $(59.6 \%)$ and $\mathrm{MCI}(37.8 \%)$ group, compared to PG $13.9 \%$ (Log-rank $p<0.001$ ).

Our hypothesis for these findings is that patients with NPS symptoms, as early manifestations of neurodegenerative diseases, tend to consult later in the course of the disease. A possible explanation for this idea is that people are generally more concerned about memory problems than in behavioral changes which are usually ignored by the patients or the family members.

From an integrative point of view, the incorporation of neuropsychiatric markers to primary care health may facilitate a synergistic development of preventive interventions. The adoption of the MBI concept along with MCI by the general physician community could lead to an advance in the knowledge of the pre-dementia diagnosis.

Another finding of this research study was that the vast majority of MCI patients tend to convert to Alzheimer's dementia while MBI patients evolve to a wider range of neurodegenerative diseases, principally FTD, followed by LBD and Alzheimer's dementia. Instead, patients in the PG evolve to LBD and FTD. Moreover, we observed that all cases of LBD were preceded by NPS (no patients evolved from MCI to LBD).

The strength of our study is the inclusion of the PG that brings novel comparison data for pre-dementia 
stages of neurodegenerative diseases. The conversion rate to dementia was significantly lower in PG patients $(13.9 \%, p<0.001)$ although they present other psychiatric disorders that could predispose to functional impairment or loss of independence. Differentiation between MBI in two subgroups (MBI with and without $\operatorname{CogS}$ ) and their rate of conversion to dementia is a novel finding.

Our study has several limitations. One of them is that our results are based on a selected group of patients referred for consultation to a dementia unit (Neuropsychiatry Research Unit, CEMIC University Hospital). Another one is that there might be overlap between the MCI with-NPS group described in this research and the MBI with-cognitive impairment group, described in our previous study [13]. Therefore, the "no cognitive complaints criterion" of the MBI diagnosis should be improved in future investigations to better differentiate these groups.

Another limitation to consider is the variability of diagnosis on behavioral impairments due to the different cultural influences. In this way, the report of behavioral symptoms could vary from one population to another but, since our research has been carried out with a homogeneous population, the study maintains cohesion and internal validity.

To conclude, the MBI concept is an advance in the diagnosis of pre-dementia populations and its identification should help in prevention and therapeutic interventions.

This study provides useful data for the diagnosis and management of pre-dementia stages with possible applications for primary care practitioners and other care and social providers in the general population.

\section{ACKNOWLEDGMENTS}

The authors wish to acknowledge the economic and scientific support afforded by the National Scientific Research Council (CONICET) from Argentina and the financial assistance of the Neuropsychiatry Research Unit, CEMIC University Hospital, Buenos Aires, Argentina.

Authors' disclosures available online (https:// www.j-alz.com/manuscript-disclosures/17-0632r2).

\section{REFERENCES}

[1] McKhann GM, Knopman DS, Chertkow H, Hyman BT, Jack CR Jr, Kawas CH, Klunk WE, Koroshetz WJ, Manly JJ, Mayeux R, Mohs RC, Morris JC, Rossor MN, Schel- tens P, Carrillo MC, Thies B, Weintraub S, Phelps $\mathrm{CH}$ (2011) The diagnosis of dementia due to Alzheimer's disease: Recommendations from the National Institute on Aging-Alzheimer's Association workgroups on diagnostic guidelines for Alzheimer's disease. Alzheimers Dement 7, 263-269.

[2] Lyketsos CG, Lopez O, Jones B, Fitzpatrick AL, Breitner J, DeKosky S (2002) Prevalence of neuropsychiatric symptoms in dementia and mild cognitive impairment. JAMA 288, 1475-1483.

[3] Modrego PJ, Ferrández J (2004) Depression in patients with mild cognitive impairment increases the risk of developing dementia of Alzheimer type: A prospective cohort study. Arch Neurol 61, 1290-1293.

[4] Geda YE, Knopman DS, Mrazek DA, Jicha GA, Smith GE, Negash S, Boeve BF, Ivnik RJ, Petersen RC, Pankratz VS, Rocca WA (2006) Depression, apolipoprotein E genotype, and the incidence of mild cognitive impairment: A prospective cohort study. Arch Neurol 63, 435-440.

[5] Rabins PV, Lyketsos CG, Steele C (1999) Practical Dementia Care, Oxford University Press, New York.

[6] Finkel SI, Costa e Silva J, Cohen G, Miller S, Sartorius N (1996) Behavioral and psychological signs and symptoms of dementia: A consensus statement on current knowledge and implications for research and treatment. Int Psychogeriatr 8, 497-500.

[7] Jeste DV, Finkel SI (2000) Psychosis and Alzheimer's disease. Am J Geriatr Psychiatry 8, 29-34.

[8] Pollero A, Allegri RF, Taragano FE (2004) Neuropsychiatric symptoms in patients with Alzheimer disease. Vertex $\mathbf{1 5}$, 5-9.

[9] Allegri RF, Sarasola D, Serrano CM, Taragano FE, Arizaga RL, Butman J, Loñ L (2006) Neuropsychiatric symptoms as a predictor of caregiver burden in Alzheimer's disease. Neuropsychiatr Dis Treat 2, 105-110.

[10] Taragano F, Allegri RF (2003) Mild behavioral impairment: The early diagnosis [abstract]. Int Psychogeriatr 15, 386.

[11] Lyketsos CG (2004) Neuropsychiatric symptoms of dementia: Nature and treatment. Presented at the 9th International Conference on Alzheimer's Disease and Related Disorders, Philadelphia.

[12] Taragano FE, Allegri RF, Lyketsos CG (2008) Mild behavioral impairment. A prodromal stage of dementia. Dement Neuropsychol 2, 256-260.

[13] Taragano FE, Allegri RF, Krupitzki H, Sarasola DR, Serrano CM, Loñ L, Lyketsos CG (2009) Mild behavioral impairment and risk of dementia: A prospective cohort study of 358 patients. J Clin Psychiatry 70, 584-592.

[14] McKhann G, Drachman D, Folstein M, Katzman R, Price D, Stadlan EM (1984) Clinical diagnosis of Alzheimer's disease: Report of the NINCDS-ADRDA Work Group under the auspices of Department of Health and Human Services Task Force on Alzheimer's Disease. Neurology 34, 939-944.

[15] The Lund and Manchester Groups (1994) Clinical and neuropathological criteria for frontotemporal dementia. J Neurol Neurosurg Psychiatry 57, 416-418.

[16] McKeith IG, Galasko D, Kosaka K, Perry EK, Dickson DW, Hansen LA, Salmon DP, Lowe J, Mirra SS, Byrne EJ, Lennox G, Quinn NP, Edwardson JA, Ince PG, Bergeron C, Burns A, Miller BL, Lovestone S, Collerton D, Jansen EN, Ballard C, de Vos RA, Wilcock GK, Jellinger KA, Perry RH (1996) Consensus guidelines for the clinical and pathologic diagnosis of dementia with Lewy bodies (DLB): Report of the consortium on DLB international workshop. Neurology 47, 1113-1124. 
[17] American Psychiatric Association (2000) Diagnostic and statistical manual of mental disorders (4th ed.). Washington, DC.

[18] Petersen RC, Smith GE, Waring SC, Ivnik RJ, Tangalos EG, Kokmen E (1999) Mild cognitive impairment: Clinical characterization and outcome. Arch Neurol 56, 303-308.

[19] Beck A, Steer R, Brown G (1996) Manual for Beck Depression Inventory II (BDI-II), Psychology Corporation, San Antonio, TX.

[20] Cummings JL, Mega M, Gray K, Rosenberg-Thompson S, Carusi DA, Gornbein J (1994) The Neuropsychiatric Inventory: Comprehensive assessment of psychopathology in dementia. Neurology 44, 2308-2314.

[21] Folstein MF, Folstein SE, McHugh PR (1975) “Mini-mental state" a practical method for grading the cognitive state of patients for the clinician. J Psychiatr Res 12, 189-198.

[22] Wechsler D (1987) WMS-R: Wechsler Memory Scale Revised Manual, Psychological Corporation, New York.

[23] Reitan RM (1958) Validity of the Trail Making Test as an indication of organic brain damage. Percept Mot Skills 8, 271-276.

[24] Allegri RF, Mangone CA, Fernández-Villavicencio A, Rymberg S, Taragano F, Baumann D (1997) Spanish boston naming test norms. Clin Neuropsychol 11, 416-420.

[25] Butman J, Allegri RF, Harris P, Drake M (2000) Spanish verbal fluency. Normative data in Argentina. Medicina ( $B$ Aires) 60, 561-564.

[26] Signoret JL, Whiteley A (1979) Memory battery scale. Int Neuropsych Soc Bull 2, 2-26.

[27] Wechsler Abbreviated Scale of Intelligence (WASI) (1999) The Psychological Corporation, San Antonio, TX.

[28] Hughes CP, Berg L, Danzinger WL, Coben LA, Martin RL (1982) A new clinical scale for the staging of dementia. $\mathrm{Br}$ J Psychiatry 140, 566-572.

[29] Morris JC (1993) The Clinical Dementia Rating (CDR): Current version and scoring rules. Neurology 43, 24122414.

[30] World Health Organization (2003) International Statistical Classification of Diseases and Related Health Problems, 10th Revision. http://apps.who.int/classifications/apps/ icd/icd10online2003/fr-icd.htm. Last accessed 19 February 2017.

[31] Canevelli M, Blasimme A, Vanacore N, Bruno G, Cesari M (2016) Mild behavioral impairment: Ethical, methodological and clinical reflections. Neurosci Biobehav Rev 69 , 402-403.

[32] Ismail Z, Smith EE, Geda Y, Sultzer D, Brodaty H, Smith G, Agüera-Ortiz L, Sweet R, Miller D, Lyketsos CG (2016) ISTAART Neuropsychiatric Symptoms Professional Interest Area. Neuropsychiatric symptoms as early manifestations of emergent dementia: Provisional diagnostic criteria for mild behavioral impairment. Alzheimers Dement 12, 195-202.

[33] Ismail Z, Agüera-Ortiz L, Brodaty H, Cieslak A, Cummings J, Fischer CE, Gauthier S, Geda YE, Herrmann N, Kanji J, Lanctôt KL, Miller DS, Mortby ME, Onyike CU, Rosenberg PB, Smith EE, Smith GS, Sultzer DL, Lyketsos C (2017) NPS Professional Interest Area of the International Society of to Advance Alzheimer's Research and Treatment (NPS-PIA of ISTAART). The Mild Behavioral Impairment Checklist (MBI-C): A rating scale for neuropsychiatric symptoms in pre-dementia populations. J Alzheimers Dis 56, 929-938.
[34] Rocca WA, Petersen RC, Knopman DS, Hebert LE, Evans DA, Hall KS, Gao S, Unverzagt FW, Langa KM, Larson EB, White LR (2011) Trends in the incidence and prevalence of Alzheimer's disease, dementia, and cognitive impairment in the United States. Alzheimers Dement 7, 80-93.

[35] Schrijvers EM, Verhaaren BF, Koudstaal PJ, Hofman A, Ikram MA, Breteler MM (2012) Is dementia incidence declining? Trends in dementia incidence since 1990 in the Rotterdam Study. Neurology 78, 1456-1463.

[36] Qiu C, von Strauss E, Bäckman L, Winblad B, Fratiglioni L (2013) Twenty-year changes in dementia occurrence suggest decreasing incidence in central Stockholm, Sweden. Neurology 80, 1888-1894.

[37] Waring SC, Rosenberg RN (2008). Genome-wide association studies in Alzheimer disease. Arch Neurol 65, 329-334.

[38] Bird T, Knopman D, VanSweiten J, Rosso S, Feldman H, Tanabe H, Graff-Raford N, Geschwind D, Verpillat P, Hutton $\mathrm{M}$ (2003) Epidemiology and genetics of frontotemporal dementia/Pick's disease. Ann Neurol 54, S29-S31.

[39] Granadillo de Luque JL, Zarante I (2008) Genética de la demencia frontotemporal. Rev Colomb Psiquiat 37, 95-113.

[40] Dillon C, Serrano CM, Castro D, Leguizamón PP, Heisecke SL, Taragano FE (2013) Behavioral symptoms related to cognitive impairment. Neuropsychiatr Dis Treat 9, 14431455.

[41] Moon B, Kim S, Park YH, Lim JS, Youn YC, Kim S, Jang JW; Alzheimer's Disease Neuroimaging Initiative (2017) Depressive symptoms are associated with progression to dementia in patients with amyloid-positive mild cognitive impairment. J Alzheimers Dis 58, 1255-1264.

[42] Sacuiu S, Insel PS, Mueller S, Tosun D, Mattsson N, Jack CR Jr, DeCarli C, Petersen R, Aisen PS, Weiner MW, Mackin RS; Alzheimer's Disease Neuroimaging Initiative (2016) Chronic depressive symptomatology in mild cognitive impairment is associated with frontal atrophy rate which hastens conversion to Alzheimer dementia. Am J Geriatr Psychiatry 24, 126-135.

[43] Demey I, Zimerman M, Allegri RF, Serrano CM, Taragano FE (2007) Neuropsychiatric symptoms in mild cognitive impairment. Vertex 18, 252-257.

[44] Mortby ME, Burns R, Eramudugolla R, Ismail Z, Anstey KJ (2017) Neuropsychiatric symptoms and cognitive impairment: Understanding the importance of co-morbid symptoms. J Alzheimers Dis 59, 141-153.

[45] Van Langenhove T, Leyton CE, Piguet O, Hodges JR (2016) Comparing longitudinal behavior changes in the primary progressive aphasias. J Alzheimers Dis 18, 1033-1042.

[46] Serrano CM, Dillon C, Castro DM, Iturry M, Rojas GJ, Bartoloni L, Taragano F, Allegri RF (2010) Neuropsychiatric symptoms in primary progressive aphasia. Rev Neurol 50, 58-59.

[47] Aygün D, Güngör IL (2015) Why is Alzheimer disease confused with other dementias? Turk J Med Sci 45, 1010-1014.

[48] Mesulam MM, Rogalski EJ, Wieneke C, Hurley RS, Geula C, Bigio EH, Thompson CK, Weintraub S (2014) Primary progressive aphasia and the evolving neurology of the language network. Nat Rev Neurol 10, 554-569.

[49] Swanberg MM, Tractenberg RE, Mohs R, Thal LJ, Cummings JL (2004) Executive dysfunction in Alzheimer disease. Arch Neurol 61, 556-560. 